\title{
Nutritional status and Cardiometabolic health among adolescents; findings from southwestern Nigeria
}

Adeleye Abiodun Adeomi (D), lyanuoluwa Odunayo Adelusi, Praise Oluwatooni Adedeji, Adedoyin Esther Awofeso, Olajumoke Omotoyosi Oroleye and Doyinfunmi Lydia Gbadegesin

\begin{abstract}
Background: Obesity has been associated with an increased risk for cardio-metabolic diseases. The prevalence of obesity among adolescents is increasing worldwide, including Nigeria, but only little data exist on the relationship of nutritional status with cardio-metabolic health among adolescents in Nigeria. This study therefore investigated the relationship of nutrition status, raised blood pressure, glucose intolerance and risk for metabolic diseases among adolescents in southwestern Nigeria.

Methods: This was a cross-sectional study conducted among 313 in-school adolescents in lle-lfe, southwestern Nigeria. The respondents were selected using multi-stage sampling technique, and data were collected using pretested structured questionnaires. Anthropometric, blood pressure and random blood glucose measurements were done using standard protocols. Nutritional assessment was done using the World Health Organization (WHO) 2007 reference. Pre-hypertension and hypertension were measured using percentiles for gender, age and height. Analysis was done using IBM SPSS and the level of significance was set at $p \leq 0.05$.

Results: The mean age of the respondents was $14.4 \pm 2.0$ years. The prevalence of overweight and obesity was $10.2 \%$, and it was significantly higher among females (12.5\%) than males (7.0\%). The prevalence of systolic and diastolic pre-hypertension was 10.9 and $11.5 \%$ respectively, while the prevalence for systolic and diastolic hypertension were 14.4 and $8.6 \%$ respectively. Using WHtR to assess cardio-metabolic risk, $7.3 \%$ of the respondents were at risk. There were statistically significant relationships between BMI, WHtR and blood pressure levels $(<0.05)$.

Conclusions: The prevalence of overweight/obesity among the adolescents was relatively high, and this was significantly associated with elevated blood pressure and increased risk for cardio-metabolic diseases. There is need for more interest and intervention by stakeholders into the cardio-metabolic health of adolescents in Nigeria.
\end{abstract}

Keywords: Nutritional status, Overweight, Obesity, Cardio-metabolic, Hypertension, Adolescents

\section{Background}

The prevalence of overweight and obesity among children and adolescents is rising all over the world [1]. The global burden of diseases project found that the prevalence of overweight/obesity among adolescents nearly doubled from 1990 to 2016, with a current prevalence of $18 \%$ [2]. It is more disturbing that this rise in the prevalence of overweight and obesity is faster in low and middle income countries (LMIC) compared to the developed countries

\footnotetext{
* Correspondence: aadeomi@cartafrica.org

Community Health Department, Obafemi Awolowo University, College of Health Sciences, Ile-Ife, Osun State, Nigeria
}

[3]. There are studies in Africa which are already reporting prevalence of overweight/obesity higher than this global average $[4,5]$.

The increasing prevalence of overweight and obesity have been attributed to nutrition transition [6]. According to Popkin [7], nutrition transition depicts the change from the traditional food patterns rich in fruits, vegetables and fibre, to what has been called the western food pattern. This western food pattern describes food rich in sugar, refined foods, saturated fats with little or low fibre. Nutrition transition also involves the reduction in energy

(c) The Author(s). 2019 Open Access This article is distributed under the terms of the Creative Commons Attribution 4.0 International License (http://creativecommons.org/licenses/by/4.0/), which permits unrestricted use, distribution, and 
expenditure and the more sedentary lifestyles brought about by technological improvements.

Nigeria is experiencing nutrition transition, with rapid urbanization and associated adoption of western diets and reducing energy expenditure among children and adolescents [8]. In the past few decades, studies on the nutritional status of children hardly reported childhood overweight or obesity [9], but this is changing in recent times. Some Nigerian studies are reporting prevalence of adolescent overweight/obesity close to the global average $[10,11]$.

The major challenge with the increasing prevalence of overweight/obesity among adolescents is the morbidity and mortality that has been associated with these nutritional states [12]. Overweight/obesity among children and adolescents has been associated with an increased risk for cardiovascular and metabolic diseases, which have been termed cardio-metabolic diseases [13, 14]. Increasing number of studies are reporting significant relationships between rising body mass index and high blood pressure, glucose intolerance and metabolic risks.

There are only few studies that have investigated the relationship between the nutritional status and the blood pressure levels of adolescents in Nigeria $[15,16]$. No study however was found in the study location that had investigated the relationship of nutritional status with glucose levels and risk for metabolic diseases (cardio-metabolic health). This study therefore investigated the relationship of nutrition status, raised blood pressure, glucose intolerance and risk for metabolic diseases among adolescents in southwestern Nigeria.

\section{Materials and methods}

\section{Study location and study population}

The study was carried out in Ile-Ife, which is an ancient city in Osun State, Southwestern Nigeria. The respondents were adolescents aged 10 to 19 years attending secondary schools in public and private schools in Ile-Ife. Adolescents who were acutely ill or had chronic illnesses like sickle cell disease anaemia that could affect their weight were excluded. Others with disabilities that made them unable to stand were also excluded.

\section{Sample size and sampling technique}

The sample size was calculated to get an absolute precision of $\pm 5 \%$ using STATCALC on the Epi-Info software. The proportion of expected outcome was taken as $22.2 \%$ which was the proportion of in-school adolescents with pre-hypertension in a similar study carried out in eastern Nigeria [16], with an acceptable margin of error of 5\%. A total of 313 adolescents were recruited from 4 secondary schools in Ile-Ife using multistage sampling technique.
Research instruments and data collection methods A self-developed, pre-tested structured questionnaire (Additional file 1) was used for data collection using the assisted self-administered method. Assessment of the socio-demographic characteristics of the adolescents, risky behaviour and self-reported history of hypertension or diabetes mellitus among the parents was done. Height was measured to the nearest $0.1 \mathrm{~m}$ using the stadiometer (Leceister ${ }^{\circ}$ Height Measure, Seca, UK), weight was measured using the $\mathrm{Seca}^{\circ}$ electronic bathroom weighing scale (SECA GmbH \& Co, Germany) and waist and hip circumferences using the Goldfish brand non-elastic tape measure. The anthropometric measurements were done according to standard protocols recommended by the International Society for the Advancement of Kinanthropometry [17].

Blood pressure was measured using the OMRON 2 digital sphygmomanometer and random blood sugar levels using OnCall Plus blood glucose meter. Blood pressure (systolic and diastolic blood pressure) was measured with the student in a sitting position, back supported, feet flat on the floor, clothing sleeve rolled back to leave upper arm uncovered, right arm supported and cubital fossa (inner elbow) approximately at heart level, having sat for at least 5 to $10 \mathrm{~min}$ to rest before measurement. Two measurements were taken $10 \mathrm{~min}$ apart, and the average was taken as the blood pressure. For the blood sugar test, single-use disposable non sterile gloves were used for each participant, as well as single-use disposable lancet device. Tests were carried out as per manufacturer's instructions. It was challenging to secure the cooperation of the adolescents to fast overnight, so the random blood sugar level was measured in millimole per litre $(\mathrm{mmol} / \mathrm{L})$. Respondents were classified such that those with blood glucose level less than 7.8 were normal, those with blood glucose level 7.8 to 11.0 had impaired glucose tolerance, greater than 11.0 had diabetes mellitus [18].

\section{Measurement of outcome variables}

Pre-hypertension was taken as systolic blood pressure (SBP) and diastolic blood pressure (DBP) $\geq 90$ th percentile, but <95th percentile for gender, age and height, while hypertension was taken as SBP and DBP $\geq 95$ th percentile for gender, age and height [19].

Nutritional status of the respondents were determined using the WHO 2007 reference for children 5-19 years. Body Mass index (BMI) was calculated by dividing the weight in kilograms by the height in meter ${ }^{2}$. BMI-forage Z-scores from the WHO reference charts were then used to classify the respondents as underweight $(<-2$ $\mathrm{SD})$, normal $(\geq-2$ to $\leq+1)$, overweight $(>+1$ to +2$)$ and obese $(>+2)$. Waist hip ratio (WHR) was calculated as waist circumference in centimeters $(\mathrm{cm})$ divided by hip circumference in $\mathrm{cm}$. WHR was classified such that 
males with ratio equal to or greater than 0.9 and females with ratio equal to or greater than 0.85 were abnormal. Risk for metabolic diseases was assessed using waist-toheight (WHtR) ratio, which has been shown to be the best predictor of cardiovascular risk and mortality [12]. WHtR was calculated by dividing waist circumference in $\mathrm{cm}$ by height in $\mathrm{cm}$, and those with $\geq 0.5$ were classified as high.

\section{Data analysis}

The questionnaires were manually sorted out, entered into a computer and the obtained data was analyzed using IBM SPSS version 20. Descriptive analysis of all the variables measured were first done, and the categorical variables were reported as frequencies and proportions/percentages, while the continuous variables were reported as means \pm standard deviation. Cross-tabulations were done to test for associations between the different categorical variables (in line with the objective of the study) using the chi-square test. Fisher's exact test was used when there was an expected value was less than 5 . Correlation analysis was done to test the strength and direction of associations between the BMI, SBP, DBP, WHR and WHtR as continuous variables. Binary logistic regression was done to identify the factors associated with elevated blood pressure. The age, sex and other factors that were significantly associated with elevated blood pressure at the bivariate analysis level were entered into the model. Logistics regression was not done for elevated blood sugar level because no factors were significantly associated at bivariate level. Level of significance was set at $p<0.05$ for this study.

\section{Ethical considerations}

Ethical clearance was obtained from the Ethical Review Committee, Institute of Public Health, Obafemi Awolowo University, Ile-Ife. Permission was obtained from the heads of the selected schools. The participants' information sheet and consent was given to the parents and the adolescents who were 18 years or above. Important information on the participants' information sheet included that the information volunteered will be kept confidential as all questionnaires were coded without names or addresses of respondents. It also emphasized that participants were free to opt-out if they were not comfortable with the information in the questionnaire. Signed consent forms were then obtained from the parents and adolescents who are 18 years and above, while assent was obtained from adolescents who were less than 18 years.

\section{Results}

The mean age of the respondents was $14.4 \pm 2.0$ years, more of them were females (58.5\%) and 243 (77.6\%) lived with both parents. Most of the respondents were from monogamamous family settings $(84.0 \%)$ with an average of $3.9 \pm 1.6$ children in their families. Concerning the occupation of the parents, 55.0 and $31.0 \%$ of the fathers were skilled (professionals) and semi-skilled (artisans) respectively, while 40.9 and $48.9 \%$ of the mothers were skilled and semi-skilled respectively. Thirteen (4.2\%) of the respondents had ever smoked, but only 4 (1.3\%) of them were current smokers. There was a history of taking alcoholic beverages among 65 (20.8\%) of them, but $22(7.0 \%)$ were currently taking alcoholic beverages. Only few of the respondents reported the history of hypertension and diabetes mellitus in their fathers $(3.8,2.9 \%)$ and mothers $(4.5,1.6 \%)$ respectively, while many of them did not know.

The age and sex distribution of overweight and obesity are shown on Table 1. Overall, $10.2 \%$ of the adolescents were overweight and obese (males $7.0 \%$, females $12.5 \%$ ). When association between the nutritional status of the adolescents was tested with their socio-demographic characteristics, gender (overweight/obese males Vs females was 9 Vs 23; $p=0.036$ ) and the mothers' occupation (overweight/ obese among the four categories of mother's occupation were $4,18,10$ and $0 ; p=0.008$ ) had statistically significant associations. This relationship was such that females and children of skilled mothers (professionals) were significantly more likely to be overweight/obese. Using random blood sugar (RBS), 6 (3.4\%) of the respondents had glucose intolerance but none was in the diabetic range. Cross tabulations of the RBS categories with potential explanatory variables yielded no statistically significant associations.

The prevalence of systolic and diastolic pre-hypertension was 10.9 and $11.5 \%$ respectively, while the prevalence for systolic and diastolic hypertension were 14.4 and $8.6 \%$ respectively. (Table 2). Table 3 shows the sex distribution of WHR, WHtR, BP and RBS, with statistically significant gender differences in WHR, WHtR and BP categories. The independent factors that were significantly associated with elevated blood pressure are as show in Table 4 . When these were entered into a binary logistic regression model, gender, current alcohol intake, BMI and WHtR categories showed statistically significant associations $(p<0.05)$. Current alcohol drinkers were 3 times (Odds ratio/Confidence interval $[\mathrm{OR} / \mathrm{CI}]=2.95 / 1.14-7.63 ; p=0.025)$ more likely than non-drinkers, females were 2 times more likely than males $(\mathrm{OR} / \mathrm{CI}=1.88 / 1.03-3.14 ; \quad p=0.036)$, overweight/obese adolescents were 6 times $(\mathrm{OR} / \mathrm{CI}=5.91 / 1.98$ 20.34; $p=0.005)$ than those underweight and those with high WHtR were 2 times $(\mathrm{OR} / \mathrm{CI}=2.05 / 0.36-6.01 ; p=$ 0.013 ) more likely than those with low WHtR to have elevated blood pressure.

There was the risk for metabolic diseases as measured by the WHtR among 23 (7.3\%) of the respondents. Gender (risk in males Vs females was 5 Vs $18 ; p=0.045$ ) was the only statistically significant explanatory variable among the socio-demographic characteristics. WHtR had a positive correlation with both systolic blood 
Table 1 Age and sex distribution of under- and over-nutrition among respondents

\begin{tabular}{|c|c|c|c|c|c|c|c|c|c|c|c|c|c|}
\hline \multirow[t]{2}{*}{ Age } & \multicolumn{4}{|c|}{ Males (\%) } & \multicolumn{4}{|c|}{ Females (\%) } & \multicolumn{5}{|c|}{ Total (\%) } \\
\hline & $\mathrm{N}$ & Uw & Ow & $\mathrm{Ob}$ & $\mathrm{N}$ & Uw & Ow & $\mathrm{Ob}$ & $N$ & Uw & Ow & $\mathrm{Ob}$ & $\mathrm{Ow} / \mathrm{Ob}$ \\
\hline 10 & 5 & 0.0 & 20.0 & 0.0 & 5 & 0.0 & 20.0 & 0.0 & 10 & 0.0 & 20.0 & 0.0 & 20.0 \\
\hline 11 & 7 & 0.0 & 0.0 & 0.0 & 11 & 18.2 & 9.1 & 0.0 & 18 & 11.1 & 5.6 & 0.0 & 5.6 \\
\hline 12 & 9 & 44.4 & 0.0 & 0.0 & 10 & 0.0 & 10.0 & 0.0 & 19 & 21.1 & 5.3 & 0.0 & 5.3 \\
\hline 13 & 10 & 20.0 & 10.0 & 0.0 & 31 & 9.7 & 16.1 & 3.2 & 41 & 12.2 & 14.6 & 2.4 & 17.0 \\
\hline 14 & 26 & 15.4 & 23.1 & 0.0 & 57 & 12.3 & 10.5 & 1.8 & 83 & 13.3 & 14.5 & 1.2 & 15.7 \\
\hline 15 & 21 & 19.0 & 0.0 & 0.0 & 30 & 10.0 & 10.0 & 0.0 & 51 & 13.7 & 5.9 & 0.0 & 5.9 \\
\hline 16 & 14 & 21.4 & 0.0 & 7.1 & 25 & 0.0 & 4.0 & 4.0 & 39 & 7.7 & 2.6 & 5.1 & 7.7 \\
\hline 17 & 24 & 4.2 & 0.0 & 0.0 & 10 & 10.0 & 10.0 & 0.0 & 34 & 5.9 & 2.9 & 0.0 & 2.9 \\
\hline 18 & 10 & 10.0 & 0.0 & 0.0 & 4 & 0.0 & 25.0 & 0.0 & 14 & 7.1 & 7.1 & 0.0 & 7.1 \\
\hline 19 & 4 & 75.0 & 0.0 & 0.0 & 0 & 0.0 & 0.0 & 0.0 & 4 & 75.0 & 0.0 & 0.0 & 0.0 \\
\hline Total & 130 & 16.9 & 6.2 & 0.8 & 183 & 8.7 & 10.9 & 1.6 & 313 & 12.1 & 8.9 & 1.3 & 10.2 \\
\hline
\end{tabular}

Uw Underweight, Ow Overweight, Ob Obesity

pressure (Correlation coefficient was $0.181 ; p=0.001$ ) and diastolic blood pressure (Correlation coefficient was $0.250 ; p<0.001$ ) and BMI (Correlation coefficient was $0.617 ; p<0.001$ ) (Table 5). The relationship between nutritional status of the respondents as measured using $\mathrm{BMI}$, and the cardio-metabolic indicators is shown on Table 6. The blood pressure (elevated BP in normal weight Vs overweight/obese is $29.2 \%$ Vs $71.9 \%$; $\mathrm{p}<$ 0.001 ) and the WHtR (high WHtR in normal weight Vs overweight/obese is $2.9 \%$ Vs $50 \%$; $\mathrm{p}<0.001$ ) were significantly associated with the nutritional status of the adolescents. Although the prevalence of abnormal WHR was highest among the overweight/obese and lowest among the underweight, this difference was not statistically significant.

Table 2 Age distribution of Pre-hypertension and hypertension among respondents

\begin{tabular}{|c|c|c|c|c|c|c|c|c|}
\hline \multirow[t]{2}{*}{ Age } & \multicolumn{4}{|c|}{ Systolic (\%) } & \multicolumn{3}{|c|}{ Diastolic (\%) } & \multirow{2}{*}{$\begin{array}{l}\text { Combined } \\
\text { EBP }\end{array}$} \\
\hline & $\mathrm{N}$ & $\mathrm{pHT}$ & $\mathrm{HT}$ & ESBP & $\mathrm{pHT}$ & $\mathrm{HT}$ & $\mathrm{EDBP}$ & \\
\hline 10 & 10 & 10.0 & 0.0 & 10.0 & 10.0 & 0.0 & 10.0 & 10.0 \\
\hline 11 & 18 & 16.7 & 5.6 & 22.2 & 5.6 & 16.7 & 22.2 & 27.8 \\
\hline 12 & 19 & 15.8 & 5.3 & 21.1 & 10.5 & 0.0 & 10.5 & 26.3 \\
\hline 13 & 41 & 2.4 & 22.0 & 24.4 & 17.1 & 14.6 & 31.7 & 41.5 \\
\hline 14 & 83 & 10.8 & 20.5 & 31.3 & 9.6 & 9.6 & 19.3 & 37.3 \\
\hline 15 & 51 & 5.9 & 17.6 & 23.5 & 5.9 & 11.8 & 17.6 & 29.4 \\
\hline 16 & 39 & 5.1 & 10.3 & 15.4 & 5.1 & 10.3 & 15.4 & 20.5 \\
\hline 17 & 34 & 8.8 & 8.8 & 17.6 & 8.8 & 0.0 & 8.8 & 26.5 \\
\hline 18 & 14 & 50.0 & 7.1 & 57.1 & 42.9 & 0.0 & 42.9 & 64.3 \\
\hline 19 & 4 & 50.0 & 0.0 & 50.0 & 75.0 & 0.0 & 75.0 & 75.0 \\
\hline Total & 313 & 10.9 & 14.4 & 25.2 & 11.5 & 8.6 & 20.1 & 32.9 \\
\hline
\end{tabular}

pHT pre-hypertension, $H T$ hypertension, EBP elevated blood pressure; combined EBP - number of respondents with systolic and/or diastolic EBP

\section{Discussion}

The overall prevalence of overweight/obesity among the adolescents was $10.2 \%$. This prevalence is higher than the country specific estimate, the regional estimate for West Africa and the global estimate by the joint child malnutrition estimates by WHO and UNICEF [1]. This prevalence is however similar to the $13.85 \%$ reported by the global burden of disease project [2]. Disparities also exist among studies carried out in Nigeria. While few of the recent studies in Nigeria have reported low prevalence of overweight/obesity $[20,21]$, more of the recent studies are reporting rates similar or even higher than the $10.2 \%$ found in this study [10, 11, 15, 22, 23]. Having

Table 3 Sex distribution of WHR, Waist categories, WHtR, BP and RBS among Respondents

\begin{tabular}{|c|c|c|c|c|}
\hline \multirow[t]{2}{*}{ Variable } & \multicolumn{2}{|c|}{ Sex distribution } & \multirow[t]{2}{*}{ Total (\%) } & \multirow[t]{2}{*}{ Statistics } \\
\hline & Males (\%) & $\overline{\text { Females (\%) }}$ & & \\
\hline$\overline{W H R}$ & & & & $x^{2}=23.81^{c}$ \\
\hline Normal & $118(90.8)$ & $123(67.2)$ & $241(77.0)$ & $d f=1$ \\
\hline Abnormal & $12(9.2)$ & $60(32.8)$ & $72(23.0)$ & $p<0.001^{a}$ \\
\hline $\mathrm{WH} \mathrm{tR}$ & & & & $x^{2}=4.01^{c}$ \\
\hline Low & $125(96.2)$ & $165(90.2)$ & $290(92.7)$ & $d f=1$ \\
\hline High & $5(3.8)$ & $18(9.8)$ & $23(7.3)$ & $p=0.045^{a}$ \\
\hline $\mathrm{BP}$ & & & & $x^{2}=4.59^{c}$ \\
\hline Normal & $96(73.8)$ & $114(62.3)$ & $210(67.1)$ & $d f=1$ \\
\hline Elevated & $34(26.2)$ & $69(37.7)$ & $103(32.9)$ & $p=0.032^{\mathrm{a}}$ \\
\hline${ }^{\mathrm{b}} \mathrm{RBS}(n=179)$ & & & & $x^{2}=0.344$ \\
\hline Normal & $66(95.7)$ & $107(97.3)$ & $173(96.6)$ & $d f=1$ \\
\hline Elevated & $3(4.3)$ & $3(2.7)$ & $6(3.4)$ & $p=0.558$ \\
\hline
\end{tabular}


Table 4 Factors associated with the Blood Pressure of the Respondents

\begin{tabular}{|c|c|c|c|c|}
\hline \multirow[t]{2}{*}{ Variable } & \multicolumn{2}{|c|}{ Blood Pressure } & \multirow[t]{2}{*}{ Total (\%) } & \multirow[t]{2}{*}{ Statistics } \\
\hline & $\overline{\text { Normal (\%) }}$ & Elevated $(\%)$ & & \\
\hline \multicolumn{3}{|l|}{ Currently smoking } & & $x^{2}=1.8^{d}$ \\
\hline Yes & $1(0.5)$ & $3(75.0)$ & $4(1.3)$ & $d f=1$ \\
\hline No & 209 (99.5) & $100(97.1)$ & 309 (98.) & $p=0.106$ \\
\hline \multicolumn{4}{|c|}{ Currently taking alcoholic beverages } & $x^{2}=5.018^{c}$ \\
\hline Yes & $10(4.8)$ & $12(11.7)$ & $22(7.0)$ & $d f=1$ \\
\hline No & $200(95.2)$ & $91(88.3)$ & $291(93.0)$ & $p=0.025^{a}$ \\
\hline \multicolumn{4}{|l|}{ WHR } & $x^{2}=0.893^{c}$ \\
\hline Normal & 165 (78.6) & $76(73.8)$ & $241(77.0)$ & $d f=1$ \\
\hline Abnormal & $45(21.4)$ & $27(26.2)$ & $72(23.0)$ & $p=0.391$ \\
\hline \multicolumn{4}{|l|}{$\mathrm{WH} t \mathrm{R}$} & $x^{2}=15.109^{c}$ \\
\hline Low & $203(96.7)$ & $87(84.5)$ & $290(92.7)$ & $d f=1$ \\
\hline High & $7(3.3)$ & $16(15.5)$ & $23(7.3)$ & $p=0.001^{a}$ \\
\hline \multicolumn{5}{|l|}{ BMI } \\
\hline Underweight & $29(13.8)$ & $9(8.7)$ & $38(12.1)$ & $x^{2}=24.971^{c}$ \\
\hline Normal & $172(81.9)$ & $71(68.9)$ & $243(77.6)$ & $d f=2$ \\
\hline Overweight/obese & $9(4.3)$ & $23(22.3)$ & $32(10.2)$ & $p<0.001^{a}$ \\
\hline \multicolumn{4}{|l|}{${ }^{b} \operatorname{RBS}(n=179)$} & $x^{2}=0.044^{d}$ \\
\hline Normal & $108(96.4)$ & $65(97.0)$ & $173(96.6)$ & $d f=1$ \\
\hline Elevated & $4(3.6)$ & $2(3.0)$ & $6(3.4)$ & $p=0.832$ \\
\hline
\end{tabular}

WHR - waist-hip ratio; WHtR - waist-to-height ratio; BMI - body mass index; RBS - random blood sugar

${ }^{\text {a }}$ statistically significant; ${ }^{\text {b }}$ only $179(57.2 \%)$ of the respondents consented to the test; ${ }^{\mathrm{C}}$ Chi-square-test used; ${ }^{\mathrm{d}}$ Fisher's exact test used

a national perspective on the prevalence of obesity in Nigeria has been challenging, especially because different studies have used differing methodologies and reference values [24]. It can however be agreed that the prevalence of overweight/obesity is rising among adolescents in Nigeria. The overall prevalence of underweight in this same adolescent population was $12.1 \%$. This typifies the double burden of disease, which is the paradoxical coexistence of under- and over-nutrition, which in this case is occurring at the population level $[3,25]$.

The significantly associated independent factors for the nutritional status of the respondents were gender and maternal occupation, such that females and children of professional mothers were more likely to be overweight/obese compared to the others. The association of gender, especially the female, has been similarly reported

Table 5 Correlation analysis between nutritional and cardiometabolic indicators

\begin{tabular}{llll}
\hline & \multicolumn{3}{l}{ Correlation coefficient $(p$-value $)$} \\
\cline { 2 - 4 } & BMI & SBP & DBP \\
\hline BMI & - & $0.388(<0.001)^{\mathrm{a}}$ & $0.255(<0.001)^{\mathrm{a}}$ \\
WHR & $0.009(0.873)$ & $0.013(0.816)$ & $0.004(0.950)$ \\
WHtR & $0.617(<0.001)^{\mathrm{a}}$ & $0.181(0.001)^{\mathrm{a}}$ & $0.250(<0.001)^{\mathrm{a}}$ \\
\hline
\end{tabular}

WHR waist-hip ratio, WHtR waist-to-height ratio; $B M I$ body mass index, SBP systolic blood pressure; DBP diastolic blood pressure a statistically significant by previous similar studies. The effect of socio-economic and wealth status of the family and childhood obesity has been well documented. The finding in this study further goes to show that the socio-economic or wealth status of the mother may be what is really responsible. This may be understandable because of the usual bond/closeness of mothers and their children. Although there was marked difference in the prevalence of nutritional status across the different ages, with $20 \%$ at 10 years, $17 \%$ at 13 and $0 \%$ at $19 \%$, these differences were however not statistically significant as was reported by other studies. This may be due to the number of respondents recruited in the different ages.

The low prevalence of glucose intolerance may be the reason why it did not show significant associations. It may not also be unrelated with the relatively small sample size of those who consented to take the test. Another possible reason may be a slower or more prolonged pathophysiology of glucose intolerance.

The prevalence of systolic and diastolic pre-hypertension was 10.9 and $11.5 \%$ respectively, while the prevalence for systolic and diastolic hypertension were 14.4 and $8.6 \%$ respectively. Overall, $32.9 \%$ had one form of elevated blood pressure or another. Similar findings, but with higher prevalence of pre-hypertension have been reported by Ejike et al. [16] in Nigeria, and Nkeh-Chungag et al. [26] in South 
Table 6 Relationship between nutritional status and cardiometabolic indicators

\begin{tabular}{|c|c|c|c|c|c|c|c|c|c|}
\hline \multirow{2}{*}{$\begin{array}{l}\text { Nutritional status } \\
\text { (BMI) }\end{array}$} & \multirow[t]{2}{*}{$\mathrm{N}$} & \multicolumn{2}{|c|}{ Blood pressure } & \multicolumn{2}{|l|}{ WHtR } & \multicolumn{2}{|l|}{ WHR } & \multicolumn{2}{|l|}{${ }^{\mathrm{b}} \mathrm{RBS}$} \\
\hline & & Normal & Elevated & Low & High & Normal & Ab-normal & Normal & Elevated \\
\hline Underweight & 38 & 76.3 & 23.7 & 100.0 & 0.0 & 81.6 & 18.4 & 94.1 & 5.9 \\
\hline Normal & 243 & 70.8 & 29.2 & 97.1 & 2.9 & 77.4 & 22.6 & 96.3 & 3.7 \\
\hline Overweight/ Obese & 32 & 28.1 & 71.9 & 50.0 & 50.0 & 68.8 & 31.2 & 100.0 & 0.0 \\
\hline Total & 313 & 67.1 & 32.9 & 92.7 & 7.3 & 77.0 & 23.0 & 96.6 & 3.4 \\
\hline \multicolumn{2}{|l|}{$p$-value } & \multicolumn{2}{|l|}{${ }^{c}<0.001^{a}$} & \multicolumn{2}{|c|}{${ }^{d}<0.001^{a}$} & \multicolumn{2}{|l|}{${ }^{c} 0.428$} & \multicolumn{2}{|l|}{${ }^{d} 0.351$} \\
\hline
\end{tabular}

WHR - waist-hip ratio; WHtR - waist-to-height ratio; BMI - body mass index; RBS - random blood sugar

${ }^{a}$ statistically significant; ${ }^{\text {b }}$ only $179(57.2 \%)$ of the respondents consented to the test; ${ }^{c}$ Chi-square-test used; ${ }^{d}$ Fisher's exact test used

Africa who reported (23.6 and 11.05\%) and (21.2 and $12.3 \%)$ respectively, for prevalence of pre-hypertension and hypertension. A much lower prevalence was reported by Omisore et al. [15] in a similar study also carried out in southwestern Nigeria. This may however be due to the fact that they used a different methodology for classifying prehypertension and hypertension among the adolescents. This rising prevalence of elevated blood pressure should be a thing of concern among stakeholders for adolescent health in Nigeria. This finding corroborates the report of the global disease burden where the prevalence of noncommunicable diseases among adolescents was put at $7.7 \%$, similar to what was reported in some wealthy countries like United States of America, Spain and China [2]. The predictors of elevated blood pressure among the adolescents were female gender, alcohol intake, overweight/obesity and risk for metabolic disease as measured by WHtR.

The risk for cardio-metabolic diseases was $7.3 \%$, as assessed by WHtR which has been found to be the best predictor of cardio-metabolic risk and mortality [12, 27], and has been used by similar studies [28]. To the best of our knowledge, this is the first study that assessed cardio-metabolic risk among adolescents using WHtR in Nigeria, hence no comparisons could be made within Nigeria. The proportion of adolescents with cardiometabolic risk using WHtR in this study is low compared to the proportion in a large sample study in China. This difference is understandable since the two countries are socio-economically different, and the particular study reported overweight/obesity rates more than twice the prevalence found in this study. However, the findings of this study similarly show associations between indicators of nutritional status (BMI), WHtR and elevated blood pressure [29]. BMI and WHtR had significant positive correlation with SBP and DBP, and WHtR had the strongest, significant positive correlation with BMI. The proportion of those with elevated BP among overweight/ obese were more than double the proportion among those with normal BMI. The proportion with high WHtR increased nearly 16 times among those with normal BMI to those overweight/obese. Another graphic representation of this relationship was the fact that half of those overweight/obese had high WHtR, while none of those underweight had high WHtR. These findings corroborates the need for monitoring of the nutritional status and cardio-metabolic risk or diseases even among adolescents [16].

The limitations of this study may include the fact that the respondents in this study were secondary school-attending adolescents in an urban community in southwestern Nigeria, generalization should therefore be done cautiously. There were only 4 respondents for age 19 and only 14 for age 18, because many of the age 18 and 19 would have left secondary school. There were relatively fewer respondents for the younger ages because of poor cooperation from them. Only 179 of the respondents consented to random glucose check, mainly for fear of needle prick, and majority did not agree to an overnight fast for fasting blood sugar.

Measurement of BP using oscilliometric devices and also on a single visit may tend to over-estimate the prevalence, and it may not be appropriate for diagnostic purposes. However, it was appropriate for the objectives of this study which was not for diagnostic nor individual interpretation rather, it was more like a screening at population level. Hence, the terms elevated blood pressure were the prominent terminology.

\section{Conclusion}

The prevalence of overweight/obesity was relatively high, higher than WHO/UNICEF estimate for Nigeria. The prevalence of elevated blood pressure was high, and significantly more among females and those overweight/ obese. The risk of cardio-metabolic diseases measured using WHtR was also relatively high, and significantly more among the overweight/obese. The nutritional status of the respondents was significantly associated with elevated blood pressure and increased risk for cardiometabolic diseases There is need for more interest and intervention by stakeholders into the cardio-metabolic health of adolescents in Nigeria. More nationally representative data is needed on the nutritional status and cardio-metabolic diseases among Nigerian adolescents. 


\section{Additional file}

Additional file 1: Questionnaire. (DOCX $20 \mathrm{~kb}$ )

\section{Abbreviations}

BMI: Body mass index; BP: Blood pressure; Cl: Confidence interval; DBP: Diastolic blood pressure; LMIC: Low and middle income countries; OR: Odds ratio; RBS: Random blood sugar; SBP: Systolic blood pressure: SPSS: Statistical Package and service solutions; UNICEF: United Nations children's fund; WHO: World Health Organization; WHR: Waist-hip ratio; WHtR: Waist to height ratio

\section{Acknowledgements}

Not applicable.

\section{Authors' contributions}

All the authors were involved in the conception of the research idea and topic. AAA, POA and DLG wrote the background of the study, IOA, AEA and OOO wrote the methodology section. All authors were involved in data collection and data entry. AAA analyzed the data, and together with IOA wrote the results and discussion sessions. All the authors read and approved the final version of the manuscript.

\section{Funding}

This research was funded by the authors.

\section{Availability of data and materials}

The datasets used and/or analyzed during the current study are available from the corresponding author on reasonable request.

\section{Ethics approval and consent to participate}

Ethical clearance was obtained from the Ethical Review Committee, Institute of Public Health, Obafemi Awolowo University, Ile-lfe. The participants' information sheet was given to the parents and the adolescents who were 16 years or above. Important information on the participants' information sheet included that the information volunteered will be kept confidential as all questionnaires were coded without names or addresses of respondents. It also emphasized that participants were free to opt-out if they were not comfortable with the information in the questionnaire. Informed written consent to participate was then obtained from the parents and adolescents who were 16 years and above, while assent was obtained from adolescents who were less than 16 years of age. Permission was obtained from the heads of the selected schools.

\section{Consent for publication}

Not applicable.

\section{Competing interests}

The authors declare that they have no competing interests.

Received: 20 May 2019 Accepted: 29 August 2019

Published online: 02 December 2019

\section{References}

1. WHO | joint child malnutrition estimates - levels and trends (2019 edition) WHO. 2019. https://www.who.int/nutgrowthdb/estimates2018/en/. Accessed 22 Apr 2019

2. Mokdad A, Kassebaum N, Lim S. Progress in adolescent health and wellbeing: tracking 12 headline indicators for 195 countries and territories, 1990-2016; Global Burden of Disease (GBD) Project. Lancet. 2019;6736: 32427-9.

3. World Health Organization (WHO). Nutrition; double burden of malnutrition. 2015. https://www.who.int/nutrition/double-burden-malnutrition/en/. Accessed 16 Apr 2019

4. Negash S, Agyemang C, Matsha TE, Peer N, Erasmus RT, Kengne AP. Differential prevalence and associations of overweight and obesity by gender and population group among school learners in South Africa : a cross-sectional study. BMC Obes. 2017:4:1-8.
5. Ngwenya NA, Ramukumba TS, Science N, Africa S, Ngwenya N. Prevalence of adolescent obesity at a high school in the City of Tshwane research setting research objectives. Curationis. 2015;40:a1662.

6. World Health Organisation (WHO). The double burden of malnutrition: policy brief. 2017. http://www.who.int/nutrition/double-burdenmalnutrition/en/. Accessed 11 Aug 2018.

7. Popkin B. Global nutrition dynamics: the world is shifting rapidly toward a diet linked with non-communicable diseases. Am J Clin Nutr. 2006:84:289-98.

8. National Population Commission (NPC) [Nigeria] and ICF International. Nigeria Demographic and Health Survey 2013. Abuja and Rockville; 2014.

9. World Health Organization (WHO). Global Health Observatory data repository; prevalence of obesity among children and adolescents. 2017 http://apps.who.int/gho/data/node.main. BMIPLUS2C?lang=en. Accessed 16 Apr 2019.

10. Adam VY, Isah JA. Prevalence and comorbidities of childhood overweight and obesity among school aged children in an urban settlement in Benin City, Nigeria. Niger J Paediatr. 2017;44(7). https:// doi.org/10.4314/njp.v44i1.2.

11. Otuneye A, Ahmed P, Abdulkarim A, Aluko O, Shatima D. Relationship between dietary habits and nutritional status among adolescents in Abuja municipal area council of Nigeria. Niger J Paediatr. 2017;44:128-35.

12. Schneider HJ, Friedrich $N$, Klotsche J, Pieper $L$, Nauck $M$, John U, et al. The predictive value of different measures of obesity for incident cardiovascular events and mortality. J Clin Endocrinol Metab. 2010;95: 1777-85.

13. Goodman E, Dolan LM, Morrison JA, Daniels SR. Factor analysis of clustered cardiovascular risks in adolescence: obesity is the predominant correlate of risk among youth. Circulation. 2005;111:1970-7.

14. Kelishadi R. Childhood overweight, obesity, and the metabolic syndrome in developing countries. Epidemiol Rev. 2007;29:62-76.

15. Omisore AG, Omisore B, Abioye-Kuteyi EA, Bello IS, Olowookere SA. Inschool adolescents' weight status and blood pressure profile in SouthWestern Nigeria: urban-rural comparison. BMC Obes. 2018;5:2. https://doi. org/10.1186/s40608-018-0179-3

16. Ejike ECC, Ugwu C, Ezeanyika L. Variations in the prevalence of point (pre) hypertension in a Nigerian school going adolescent population living in a semi-urban and urban area. BMC Paediatr. 2010;10:10-3.

17. International Society for the Advancement of Kinanthropometry. International Standards for anthropometric Assessment; 2001. p. 53-5.

18. American Diabetes Association. Definition and description of diabetes other categories of glucose. Diabetes Care. 2010;33:562-9.

19. National High Blood Pressure Education Program. Fourth report on the diagnosis, evaluation, and treatment of high blood pressure in children and adolescents. Peadiatrics. 2004:114:555-76.

20. Abah RO, Okolo SN, John C, Ochoga MO, Adah RO. Nutritional status of schoolchildren in Jos east local government area of plateau state, north Central Nigeria. J Med Trop. 2017;19:56-9.

21. Oyeyemi ALALAY, Ishaku CM, Oyekola J, Wakawa HD, Lawan A, Yakubu $S$, et al. Patterns and associated factors of physical activity among adolescents in Nigeria. PLoS One. 2016;11:1-16. https://doi.org/10.1371/ journal.pone.0150142

22. Sadoh WE, Sadoh AE, Uduebor JE, Shaibu M, Ogonor E, Enugwuna FC, et al. Comparison of obesity, overweight and elevated blood pressure in children attending public and private primary schools in Benin City, Nigeria. Niger J Clin Pract. 2017;20:839-46.

23. Eze JN, Oguonu T, Ojinnaka NCIB. Physical growth and nutritional status assessment of school children in Enugu, Nigeria. Niger J Clin Pract. 2017;20:64-70.

24. Ejike CCC. Child and adolescent obesity in Nigeria: a narrative review of prevalence data from three decades (1983-2013). J Obes Metab Res. 2014;1: 174. https://doi.org/10.4103/2347-9906.141150.

25. Doak CM, Adair LS, Bentley M, Monteiro C, Popkin BM. The dual burden household and the nutrition transition paradox. Int J Obes. 2005;29:129-36.

26. Nkeh-Chungag BN, Sekokotla AM, Sewani-Rusike C, Namugowa A, Iputo JE. Prevalence of hypertension and pre-hypertension in 13-17 year old adolescents living in Mthatha-South Africa: a cross-sectional study. Cent Eur J Public Health. 2015;23:59-64. https://doi.org/10.21101/cejph.a3922.

27. Ashwell M, Gunn P, Gibson S. Waist-to-height ratio is a better screening too than waist circumference and BMl for adult cardiometabolic risk factors systematic review and meta-analysis. Obes Rev. 2012;13:275-86. 
28. Pisa PT, Pedro TM, Kahn K, Tollman SM, Pettifor JM, Norris SA. Nutrient patterns and their association with socio-demographic, lifestyle factors and obesity risk in rural south African adolescents. Nutrients. 2015;7:3464-82.

29. Song P, Li X, Gasevic D, Flores AB, Yu Z. BMI, waist circumference reference values for Chinese school-aged children and adolescents. Int J Environ Res Public Health. 2016;13:1-13.

\section{Publisher's Note}

Springer Nature remains neutral with regard to jurisdictional claims in published maps and institutional affiliations.

Ready to submit your research? Choose BMC and benefit from:

- fast, convenient online submission

- thorough peer review by experienced researchers in your field

- rapid publication on acceptance

- support for research data, including large and complex data types

- gold Open Access which fosters wider collaboration and increased citations

- maximum visibility for your research: over $100 \mathrm{M}$ website views per year

At BMC, research is always in progress.

Learn more biomedcentral.com/submissions 